\title{
Impact of male infertility on men's self-esteem
}

\author{
Original \\ Emad Eldien Kamal', Nadia Abd El-Ghany², Saleh Omar Abdulla', Aya Y. Badran \\ Article \\ ${ }^{1}$ Departments of Dermatology, Venereology and Andrology, Faculty of Medicine, ${ }^{2}$ Faculty of \\ Nusring, Assiut University, Assiut, Egypt
}

\begin{abstract}
Background: : Self-esteem is based on an individual's appraisal or estimation of his / her importance or value. Since infertility causes personal, familial, and social problems, it considered a devastating health problem. Infertile males experience considerable psychological stress, with low self esteem, isolation, loss of control, sexual inadequacy and depression.

Objective: To assess impact of male infertility on self-esteem and determine relationship between clinical, demographic characteristics and self-esteem of infertile males.

Patients and Methods: A non experimental (case-control) research design used to conduct this study. A purposive sample was used. The current study included 150 subjects, 100 was studied group \& 50 was control group. Data collection tool consisted two parts:1-Demographic and clinical data sheet, 2- Modified form (Rosenberg Self-Esteem Scale (RSES).

Results: The most of fertile and infertile age groups was from 28 to $<38$ years old. $65 \%$ of infertile males and $58 \%$ of fertile males were from rural area. About $63 \%$ of infertile males were primary infertility. As well as $56 \%$ of infertile males were $1-3$ years. $74 \%$ of infertile males were smoked. There were highly statistically significant difference between level of self-esteem among infertile and fertile males $\left(p=0.000^{* *}\right)$.

Conclusion: From the present study, we can conclude that infertile males were having low self-esteem than fertile males making them more liable to having personal as well as social problems.
\end{abstract}

Key Words: Demographic data, infertile couples, male infertility, RSES, self-esteem.

Received: 11 April 2019, Accepted: 22 November 2019.

Corresponding Author: Aya Youssef Badran, Assuit University Hospital, Egypt, Tel.: 01013244819, E-mail: Aya_badran@yahoo.com

ISSN: 2090-6048, June 2019 Vol.9, No.2

\section{INTRODUCTION}

Infertility is the inability to achieve a successful pregnancy after 12 months of unprotected intercourse or therapeutic donor insemination. It is a global phenomenon affecting between 60 million and 168 million people worldwide ${ }^{[1]}$. In Egypt, the prevalence of infertility using world health organization (WHO) definition has been estimated to be between $10 \%$ to $15 \%$ among married couples $^{[2]}$. It considered a social problemaffecting the individual, family, and society, yet it not a life-threatening disease $^{[3]}$.

Self-esteem is an essential element in an individual's mental and physical health. It defined as a positive or negative attitude towards oneself. Self-esteem is based on evaluation of self-characteristics, feelings of selfsatisfaction and self-acceptance ${ }^{[4]}$.

Self-esteem is divided between low self-esteem (LSE) and high self-esteem (HSE). Low self-esteem individuals are susceptible to external influences, whereas people with high self-esteem are less susceptible to external influences ${ }^{[5]}$.

Infertility has important effects on self-esteem. Infertility as an emotional crisis for most, with anger, guilt, depression and loss of self-esteem. Self-esteem is linked to productivity and that illness, pain, and infertility is associated with low level of self-esteem. Low self-esteem followed by a sense of hopelessness and despair ${ }^{[6]}$.

\section{PATIENTS AND METHODS}

We performed a non-experimental (case-control) study at outpatient clinic of andrology and STDs in Assiut University Hospital. 150 subjects were included, 100 of them was studied group and 50 of them was control group. All infertile males who attended the out-patients clinics of andrology and STDs in Assiut University Hospital during six months, from December 2015 till end of May 2016 were included in the study, we used fifty normal fertile males 
who attended the clinics to other causes as control group. While, we excluded patients with systematic diseases and patients with psychological problems or mental disorders. The study was approved by the ethical committee of the Faculty of Medicine, Assiut University. All patients signed a written informed consent.

Study tools: The study tool consisted of two parts:The Demographic and Clinical data sheet and Modified form (Rosenberg Self-Esteem Scale (RSES).

The demographic data included (age, address, religious, occupation, level of education). While, the clinical data included (types and duration of infertility, previous operation for infertility, previous ICSI, semen data for azoospermic or non azoospermic and special habits).

The Modified form (Rosenberg Self-Esteem Scale (RSES) is a scale adopted from (Rosenberg 1965).This questionnaires modified by Savard et al., $(2000)^{[7]}$ is obviously the most widely used instrument in field of scientific research and clinical practice for the measurement of global self-esteem, understood as a person's overall evaluation of his or her worthiness as a human being (Mcmullen and Resnick, 2013) ${ }^{[8]}$. It composed of 10 items, 5 positive and 5 negative and scored on a 4 likert Scale which are: Strongly agree, Agree, Disagree and Strongly disagree

Scores are calculated as follows: For items 1, 2, 4, 6 and 7: Strongly agree $=3$, Agree $=2$, Disagree $=1$ and strongly disagree $=0$. While, for items $3,5,8,9$ and 10 (which are reversed in valence): Strongly agree $=0$, Agree $=1$, Disagree $=2$ and strongly disagree $=3$. Scoring (add the SS below will give you an idea of the level of self-esteem :

The scale ranges from 0-30. Scores 'between' 15 to 25 are within normal range; Scores 'between' 25-30 are within high self-esteem, scores below 15 suggest low self- esteem.

The scale was reported to have high reliability as evidence by Cronbach's Alpha was $r=0.73$ for the total scale. The Arabic translation and validation were done by (Arafa et al., 2015) ${ }^{[9]}$, Women College, Ain Shams University.

\section{Statistical design:}

All analyses were performed with the IBM SPSS 20.0 software. The data were tested for normality using the Anderson-Darling test and for homogeneity variances prior to further statistical analysis. Categorical variables were described by number and percent $(\mathrm{N}, \%)$, where continuous variables described by mean and standard deviation (Mean, SD). Chi-square test and fisher exact test used to compare between categorical variables where compare between continuous variables by t-test. Pearson correlation coefficient used to assess the association between continuous variables. A two-tailed $p<0.05$ was considered statistically significant.

\section{RESULTS}

Regarding the demographic data of the infertile and fertile males, we found that the mean age of infertile males was $35+7.6$ years compared with $33.2+7.3$ years of fertile group. The most of fertile and infertile age groups was from 28 to $<38$ years old. $65 \%$ of infertile males and $58 \%$ of fertile males were from rural area. More than quarters (28\%) of infertile males were farmer while $24 \%$ of fertile males were employee and $24 \%$ manual work. $31 \%$ of infertile males were secondary level of education while $42 \%$ of fertile males were universal level. All demographic data were not statistically significant difference between infertile and a fertile males (Table 1).

Table 1: Demographic data of the infertile $(\mathrm{N}=100)$ and fertile males $(\mathrm{N}=50)$.

\begin{tabular}{|c|c|c|c|c|c|}
\hline & \multicolumn{2}{|c|}{$\begin{array}{l}\text { Infertile males } \\
\text { (Studied group) } \\
\mathrm{N}=(100)\end{array}$} & \multicolumn{2}{|c|}{$\begin{array}{c}\text { Fertile males } \\
\text { (Control group) } \\
\mathrm{N}=(50)\end{array}$} & \multirow[t]{2}{*}{$P$ value } \\
\hline & No. & $\%$ & No. & $\%$ & \\
\hline Age, Mean \pm SD & \multicolumn{2}{|c|}{$35+7.6$} & \multicolumn{2}{|c|}{$33.2+7.3$} & 0.172 \\
\hline \multicolumn{6}{|c|}{ Age groups } \\
\hline $18-<28$ years & 24 & 24.0 & 11 & 22.0 & \multirow{3}{*}{0.578} \\
\hline $28-<38$ years & 52 & 52.0 & 23 & 46.0 & \\
\hline$\geq 38$ years & 24 & 24.0 & 16 & 32.0 & \\
\hline \multicolumn{6}{|c|}{ Residence } \\
\hline Urban & 35 & 35.0 & 21 & 42.0 & \multirow{2}{*}{0.403} \\
\hline Rural & 65 & 65.0 & 29 & 58.0 & \\
\hline
\end{tabular}




\begin{tabular}{|c|c|c|c|c|c|c|c|}
\hline \multicolumn{8}{|c|}{ Religion } \\
\hline Muslim & & 98 & & & 50 & 100.0 & \multirow{2}{*}{0.314} \\
\hline Christian & & 2 & & & 0 & 0.0 & \\
\hline \multicolumn{8}{|c|}{ Occupation } \\
\hline Not work & 13 & & 13.0 & 7 & & 14.0 & \multirow{6}{*}{0.545} \\
\hline Student & 5 & & 5.0 & 4 & & 8.0 & \\
\hline Employee & 20 & & 20.0 & 12 & & 24.0 & \\
\hline Manual work & 26 & & 26.0 & 12 & & 24.0 & \\
\hline Professional work & 8 & & 8.0 & 7 & & 14.0 & \\
\hline Farmer & 28 & & 28.0 & 8 & & 16.0 & \\
\hline \multicolumn{8}{|c|}{ Level of education } \\
\hline Illiterate/read and write & 23 & & 23.0 & 7 & & 14.0 & \multirow{5}{*}{0.220} \\
\hline Primary & 10 & & 10.0 & 5 & & 10.0 & \\
\hline Preparatory & 12 & & 12.0 & 4 & & 8.0 & \\
\hline Secondary & 31 & & 31.0 & 13 & & 26.0 & \\
\hline Universal & 24 & & 24.0 & 21 & & 42.0 & \\
\hline
\end{tabular}

$\mathrm{T}$ - Test for mean, Chi-square test for numbers

As regards the clinical data of infertile males as shown in Table 2) which indicated that $63 \%$ of infertile males were primary infertility. Mean $\pm \mathrm{SD}$ according to duration of infertility were $3.95+2.8$ years. Regarding duration of infertility more than half $(56 \%)$ of infertile males were 1-3 years. The quarter (25\%) of infertile males were having previous operations for infertility. While $23 \%$ of them were having previous ICSI Regarding of semen analysis about $20 \%$ of infertile males were azoospermic semen analysis. Regarding special habits, $74 \%$ of infertile males were smoked.

Table 2: Clinical data of infertile males $(\mathrm{N}=100)$

\begin{tabular}{|c|c|c|}
\hline \multirow{2}{*}{ Variables } & \multicolumn{2}{|c|}{$\begin{array}{c}\text { Infertile males } \\
\text { (Studied group) } \mathrm{N}=(100)\end{array}$} \\
\hline & No. & $\%$ \\
\hline \multicolumn{3}{|c|}{ Type of infertility } \\
\hline Primary & 63 & 63.0 \\
\hline Secondary & 37 & 37.0 \\
\hline \multicolumn{3}{|c|}{ Duration of infertility } \\
\hline Mean \pm SD & \multicolumn{2}{|c|}{$3.95+2.80$} \\
\hline $1-3$ years & 56 & 56.0 \\
\hline 4-6 years & 26 & 26.0 \\
\hline$\geq 7$ years & 18 & 18.0 \\
\hline \multicolumn{3}{|c|}{ Previous operations for infertility } \\
\hline Yes & 25 & 25.0 \\
\hline No & 75 & 75.0 \\
\hline
\end{tabular}




\begin{tabular}{lcc}
\hline & Previous ICSI & 23.0 \\
Yes & 23 & 77.0 \\
No & 77 & 20.0 \\
& Semen analysis & 80.0 \\
Azoospermic & 20 & 22.0 \\
Non Azoospermic & 80 & 74.0 \\
& Special habits & 4.0 \\
Not smoking or drugs & 22 & 4 \\
Smoking & 74 & 4 \\
\hline
\end{tabular}

- Chi-square test

-** Highly statistically significant difference $(p<0.01)$

Regarding the levels of Rosenberg self-esteem scale among infertile and fertile males, we found that $47 \%$ of infertile males were low self-esteem while $49 \%$ of infertile males normal self-esteem. The most of fertile males were normal self-esteem (80\%). There were highly statistically significant difference between level of self-esteem among infertile and fertile males ( $\left.p=0.000^{* *}\right)$.

Regarding the relationship between demographic data and levels of Rosenberg self-esteem scale among infertile and fertile males, we found that there were highly statistical significant differences between demographic data and levels of Rosenberg self-esteem scale among infertile males except age. There were no statistically significant differences between demographic data and levels of Rosenberg self-esteem scale among fertile males as shown in (Table 3). And as regards the relationship between clinical data and levels of Rosenberg self-esteem scale among infertile males, there was no statistical significant differences between clinical data and levels of Rosenberg self-esteem scale of infertile males except in semen analysis $(p=0.017)$ (Table 4).

Table 3: Relationship between demographic data and levels of Rosenberg self-esteem scale among infertile $(\mathrm{N}=100)$ and fertile males $(\mathrm{N}=50)$

\begin{tabular}{|c|c|c|c|c|c|c|c|c|c|c|c|c|c|c|}
\hline \multirow{4}{*}{ Variables } & \multicolumn{7}{|c|}{ Infertile males (Study group $\mathrm{n}=100$ ) } & \multicolumn{7}{|c|}{ Fertile males (Control group $\mathrm{n}=50$ ) } \\
\hline & \multicolumn{6}{|c|}{ Levels self esteem } & & \multicolumn{6}{|c|}{ Levels self esteem } & \multirow{4}{*}{$\begin{array}{c}P \\
\text { value }\end{array}$} \\
\hline & \multicolumn{2}{|c|}{$\begin{array}{l}\text { High self } \\
\text { esteem }\end{array}$} & \multicolumn{2}{|c|}{$\begin{array}{l}\text { Normal self } \\
\text { esteem }\end{array}$} & \multicolumn{2}{|c|}{$\begin{array}{l}\text { Low self } \\
\text { esteem }\end{array}$} & \multirow{2}{*}{$P$ value } & \multicolumn{2}{|c|}{$\begin{array}{l}\text { High self } \\
\text { esteem }\end{array}$} & \multicolumn{2}{|c|}{$\begin{array}{l}\text { Normal self } \\
\text { esteem }\end{array}$} & \multicolumn{2}{|c|}{$\begin{array}{l}\text { Low self } \\
\text { esteem }\end{array}$} & \\
\hline & No. & $\%$ & No. & $\%$ & No. & $\%$ & & No. & $\%$ & No. & $\%$ & No. & $\%$ & \\
\hline Total & 4 & 4.0 & 49 & 49.0 & 47 & 47.0 & & 6 & 12.0 & 40 & 80.0 & 4 & 8.0 & \\
\hline \multicolumn{15}{|c|}{ Age groups } \\
\hline $18-<28$ years & 2 & 50.0 & 10 & 20.4 & 12 & 25.5 & \multirow{3}{*}{0.716} & 2 & 33.3 & 8 & 20.0 & 1 & 25.0 & \multirow{3}{*}{0.895} \\
\hline $28-<38$ years & 1 & 25.0 & 27 & 55.1 & 24 & 51.1 & & 3 & 50.0 & 18 & 45.0 & 2 & 50.0 & \\
\hline 38 years and more & 1 & 25.0 & 12 & 24.5 & 11 & 23.4 & & 1 & 16.7 & 14 & 35.0 & 1 & 25.0 & \\
\hline \multicolumn{15}{|c|}{ Residence } \\
\hline Urban & 3 & 75.0 & 28 & 57.1 & 4 & 8.5 & \multirow{2}{*}{$0.000^{* *}$} & 4 & 66.7 & 16 & 40.0 & 1 & 25.0 & \multirow{2}{*}{0.361} \\
\hline Rural & 1 & 25.0 & 21 & 42.9 & 43 & 91.5 & & 2 & 33.3 & 24 & 60.0 & 3 & 75.0 & \\
\hline
\end{tabular}




\begin{tabular}{|c|c|c|c|c|c|c|c|c|c|c|c|c|c|c|}
\hline \multicolumn{15}{|c|}{ Religion } \\
\hline Muslim & 4 & 100.0 & 49 & 100.0 & 45 & 95.7 & \multirow{2}{*}{0.316} & 6 & 100.0 & 40 & 100.0 & 4 & 100.0 & \multirow{2}{*}{ - } \\
\hline Christian & 0 & 0.0 & 0 & 0.0 & 2 & 4.3 & & 0 & 0.0 & 0 & 0.0 & 0 & 0.0 & \\
\hline \multicolumn{15}{|c|}{ Occupation } \\
\hline Not work & 1 & 25.0 & 3 & 6.1 & 9 & 19.1 & \multirow[b]{4}{*}{$0.001^{* *}$} & 0 & 0.0 & 7 & 17.5 & 0 & 0.0 & \multirow{6}{*}{0.151} \\
\hline Student & 0 & 0.0 & 5 & 10.2 & 0 & 0.0 & & 0 & 0.0 & 4 & 10.0 & 0 & 0.0 & \\
\hline Employee & 0 & 0.0 & 14 & 28.6 & 6 & 12.8 & & 1 & 16.7 & 10 & 25.0 & 1 & 25.0 & \\
\hline Manual work & 0 & 0.0 & 12 & 24.5 & 14 & 29.8 & & 3 & 50.0 & 6 & 15.0 & 3 & 75.0 & \\
\hline Professional work & 2 & 50.0 & 6 & 12.2 & 0 & 0.0 & & 2 & 33.3 & 5 & 12.5 & 0 & 0.0 & \\
\hline Farmer & 1 & 25.0 & 9 & 18.4 & 18 & 38.3 & & 0 & 0.0 & 8 & 20.0 & 0 & 0.0 & \\
\hline \multicolumn{15}{|c|}{ Level of education } \\
\hline $\begin{array}{l}\text { Illiterate/read and } \\
\text { write }\end{array}$ & 0 & 0.0 & 2 & 4.1 & 21 & 44.7 & & 0 & 0.0 & 7 & 17.5 & 0 & 0.0 & \multirow{5}{*}{0.282} \\
\hline Primary & 0 & 0.0 & 4 & 8.2 & 6 & 12.8 & & 1 & 16.7 & 4 & 10.0 & 0 & 0.0 & \\
\hline Preparatory & 1 & 25.0 & 3 & 6.1 & 8 & 17.0 & $0.000^{* *}$ & 1 & 16.7 & 3 & 7.5 & 0 & 0.0 & \\
\hline Secondary & 1 & 25.0 & 22 & 44.9 & 8 & 17.0 & & 0 & 0.0 & 10 & 25.0 & 3 & 75.0 & \\
\hline Universal & 2 & 50.0 & 18 & 36.7 & 4 & 8.5 & & 4 & 66.7 & 16 & 40.0 & 1 & 25.0 & \\
\hline
\end{tabular}

Table 4: Relationship between clinical data and levels of Rosenberg self-esteem scale among infertile males (N=100).

\begin{tabular}{|c|c|c|c|c|c|c|c|}
\hline \multirow{3}{*}{ Variables } & \multicolumn{6}{|c|}{ Levels self esteem } & \multirow{3}{*}{$P$. value } \\
\hline & \multicolumn{2}{|c|}{ High self esteem } & \multicolumn{2}{|c|}{ Normal self esteem } & \multicolumn{2}{|c|}{ Low self esteem } & \\
\hline & No. & $\%$ & No. & $\%$ & No. & $\%$ & \\
\hline Total & 4 & 4.0 & 49 & 49.0 & 47 & 47.0 & \\
\hline \multicolumn{8}{|c|}{ Type of infertility } \\
\hline Primary & 2 & 50.0 & 26 & 53.1 & 35 & 74.5 & \multirow{2}{*}{0.081} \\
\hline Secondary & 2 & 50.0 & 23 & 46.9 & 12 & 25.5 & \\
\hline \multicolumn{8}{|c|}{ Duration of infertility } \\
\hline $1-3$ years & 3 & 75.0 & 30 & 61.2 & 23 & 48.9 & \multirow{3}{*}{0.135} \\
\hline 4-6 years & 1 & 25.0 & 15 & 30.6 & 10 & 21.3 & \\
\hline$\geq 7$ years & 0 & 0.0 & 4 & 8.2 & 10 & 21.3 & \\
\hline 10 years and more & 0 & 0.0 & 0 & 0.0 & 4 & 8.5 & \\
\hline \multicolumn{8}{|c|}{ Previous operations for infertility } \\
\hline Yes & 1 & 25.0 & 13 & 26.5 & 11 & 23.4 & \multirow{2}{*}{0.939} \\
\hline No & 3 & 75.0 & 36 & 73.5 & 36 & 76.6 & \\
\hline
\end{tabular}


Previous ICSI

\begin{tabular}{lccccccc} 
Yes & 0 & 0.0 & 9 & 18.4 & 14 & 29.8 & 0.222 \\
No & 4 & 100.0 & 40 & 81.6 & 33 & 70.2 & \\
& & & & & \\
\\
Azoospermic & 0 & 0.0 & 5 & 10.2 & 15 & 31.9 & $0.017^{*}$ \\
Non Azoospermic & 4 & 100.0 & 44 & 89.8 & 32 & 68.1 & \\
& & & Special habits & & & \\
Not smoking or drugs & 2 & 50.0 & 15 & 30.6 & 5 & & \\
Smoking & 2 & 50.0 & 33 & 67.3 & 39 & 83.0 & 0.083 \\
Hashish & 0 & 0.0 & 1 & 2.0 & 3 & 6.4 & \\
\hline
\end{tabular}

Chi-square test

* Statistically significant difference $(p<0.05)$

\section{DISCUSSION}

The physical, psychological, ethical,emotional, and financial effects of infertility have been studied inan abundance of studies in both males and females. Infertile couplesfrequently have signs of stress, anxiety, depression, guilt feeling, fear and loss of social status which may appear in their behavior ${ }^{[10]}$.

Regarding the age, the current study findings showed that mean age of infertile males were $(35+7.6)$ years, compared with fertile males were $(33.2+7.3)$ years. These findings are similar to previous studies reported by Gulec et al. ${ }^{[11]}$ who found that mean age of infertile males were $35+6.4$ compared with fertile males were $(34$. $+4.5)$ years. Also, Yusuf et $a .^{[12]}$ found that mean age of infertile males were $(35+6.7)$ years. Whereas, these findings are contradicted with other studies reported by Abolfotouh et $a l^{[13]}$ who found that mean age of fertile males were $36+11.1$ years. Also, Galhardo, et al 14 found that mean age of infertile males were $(34+7.6)$ years compared with fertile males were $(35 .+4.4)$ years.

The current study found that about two thirds of infertile males were primary infertility. These findings are similar with previous studies reported by Wischmann et al.,15 found that about two thirds of infertile males were primary infertility. Also (Broeck et al. ${ }^{[16]}$, Ketabchi ${ }^{[17]}$, Omu, et al. ${ }^{[18]}$, Ahmadi et al. ${ }^{[19]}$ and Gao et al. ${ }^{[20]}$ found that most of infertile males were primary infertility.

The present study revealed that about less than one quarter of infertile males was azoospermic semen analysis. In the respect with previous study reported by Abolfotouh et al. ${ }^{[13]}$ found that $7 \%$ of infertile males were azoospermic semen analysis. While, Gadalla et al. ${ }^{[21]}$ found that about one quarter of infertile males were azoospermic semen analysis. The present study showed that about more than two thirds of infertile males were smoked. This may be related to the smoking adverse influence on semen quality specialty among heaving smokers. These finding are similar with previous studies reported by Gao et $a{ }^{\left[{ }^{[20]}\right.}$ and Ahmadi et al. ${ }^{[19]}$ found that about more than two thirds of infertile males were smokeers. Also, these findings are disagreement with other study reported by Zorn et al. ${ }^{[22]}$ found that about one thirds of infertile males were smokeres.

The current study showed that less than half of the infertile were low self-esteem. While, the most of fertile males were normal self-esteem. This may be due to infertility has deeply effect on male self-esteem. This can be explained when the male are faced the inability to become father, in addition feeling associated with a positive sense of identity, self-esteem and self-image are threatened, as well as low self-esteem displayed as feeling of inadequate and inferior to the most people they know. However, there statistically significant difference between level of self-esteem among infertile and fertile males $\left(p=0.000^{* *}\right)$. These findings are similar with Sultan, and Tahir, (2011) ${ }^{[23]}$ who showed that high percent of the infertile compared fertile males with low self-esteem. Furthmore, there were statistically significant difference between level of self-esteem among infertile and fertile males $\left(p=0.000^{* *}\right)$. Also, Wischmann et al ${ }^{[15]}$ found that half of the infertile males were low self-esteem

While, these findings are contradicted with other study reported by Keramat et al. ${ }^{[24]}$ who stated thatthe majority of the infertile males were normal self-esteem. In the 
same line, Xing et al. ${ }^{[25]}$ found that there were statistically significant difference between level of self-esteem among infertile and fertile males.

The current study showed that, there statistical significant differences between demographic data and levels of Rosenberg self-esteem scale among infertile males except age group. Otherwise, there were no statistically significant differences between demographic data and levels of Rosenberg self-esteem scale among fertile males.

The previous results supported by Sultan, and Tahir $^{[23]}$ showed that, there are no statistically significant differences between age group and self-esteem among infertile and fertile males. While, there was statistically significant differences between education level and self-esteem among infertile compared fertile males there were no statistically significant differences. On the contrary Xing et al. ${ }^{[25]}$ found that there are no statistically significant differences between age group and self-esteem among infertile males. While, there were statistically significant differences between education level and self-esteem among infertile males. Also, Keramat et al. ${ }^{[24]}$ results were disagree with our studyas they found that, there was no statistically significant differences between demographic data (age group, residence, occupation and educational level) and self-esteem among infertile males.

The current study found that there were statistical significant relation between semen analysis and self-esteem. The researcher observed that infertile males with non azoospermic (present of sperm) and secondary infertility were having normal self-esteem than infertile males with Azoospermic and primary infertility because they were already get child. So they have a hope to be pregnant his wife again because they feel that are normal and have a healthy body. This finding supported by Keramat et al. ${ }^{[24]}$ whose found that there association between self-esteem and type of infertility.

\section{RECOMMENDATIONS}

Based on the current study findings, we do recommend that psycho-education program should be designed, constructed and administered to the infertile males to improve self-esteem, also, highly specialized infertility clinic should be established to provide psychological support and counseling to all infertile males. Lastly, the presence of psychiatrists and psychologists in the treatment of emotional and psychological problems of the males are of great importance.

\section{REFERENCES}

1. Practice Committee of the American Society for Reproductive Medicine. (2013). Definitions of infertility and recurrent pregnancy loss: a committee opinion. Fertility and sterility, 99(1), 63.

2. Mokhtar, S., Hassan, H. A., and Mahdy, N. (2012). Risk Factors For Primary and Secondary Female Infertility in Alexandria: A Hospital Based Case-Control study. J Med Res Inst, 27(4), 245-252.

3. Kirca N, Pasinoglu T. Psychosocialproblems during infertility treatment.Current Approaches in Psychiatry. 2013;5(2):162-178.

4. Hewitt, and John P. (2009). Oxford Handbook of Positive Psychology. Oxford University Press. pp. 217-224. ISBN 978-0-19-518724-3.

5. Mamata, D., Ray, S. K., Pratap, K., Firuza, P., Birla, A. R., and Manish, B. (2015). Impact of different controlled ovarian stimulation protocols on the physical and psychological burdens in women undergoing in vitro fertilization/intra cytoplasmic sperm injection. Journal of Human Reproductive Sciences, 8(2), 86-92.

6. Jacob MC, Quillan J, Greil AL(2007). Psychological distress by type of fertility barrier. Human Reprod; 22:885-894.

7. Savard, J., Laberge, B., Gautheir,J.G., Ivers, H. and Bergeron, M.G. (2000)."Selfesteem: Clinical assessment and measurement validation. psychological reports, 16(3),1017-1071.

8. McMullen, T., and Resnick, B. (2013). Self-esteem among nursing assistants: reliability and validity of the Rosenberg self-esteem scale. Journal of nursing measurement, 21(2), 335-344.

9. Arafa, S., Ibrahim, A., and Farouk, S. (2015). The Effectiveness of a program for Enhancement Working Memory and it on some Psychological Variables in the Elderly (Doctoral thesis). Women College - Ain Shams University.

10. Cousineau TM, Domar A.Psychological impact of infertility. BestPractice and Research: Clinical Obstetrics and Gynaecology. 2007;21(2):293-308.

11. Gulec, G., Hassa, H., Yalcin, E. G., and Yenilmez, C. (2011). Evaluation of the effect of infertility on sexual functions and couple adjustment in infertile couples who seek treatment. Turkish Journal of Psychiatry, 18(1),1-11

12. Yusuf, a. J., Maitama, H. Y., Amedu, M. a., Ahmed, 
M., and Mbibu, H. N. (2012). Socio-demographic correlates of psychological distress among male patients with infertility in Zaria, Nigeria. African Journal of Urology, 18(4), 170-174.

13. Abolfotouh, M. A., Alabdrabalnabi, A. A., Albacker, R. B., Al-Jughaiman, U. A., and Hassan, S. N. (2013). Knowledge, attitude, and practices of infertility among Saudi couples. International Journal of General Medicine, 6, 563-573.

14. Galhardo, A., Pinto-Gouveia, J., Cunha, M. and Matos, M. (2011). The impact of shame and selfjudgment on psychopathology in infertile patients. Human Reproduction, 96, 9, 2408-2414.

15. Wischmann, T., Schilling, K., Toth, B., Rosner, S., Strowitzki, T., Wohlfarth, K., and Kentenich, H. (2014). Sexuality, Self-Esteem and Partnership Quality in Infertile Women and Men. Geburtshilfe Frauenheilkd, 74(8), 759-763.

16. Broeck, U. V., D'hooghe, T., Enzlin, P., and Demyttenaere, K. (2010). Predictors of psychological distress in patients starting IVF treatment: Infertilityspecific versus general psychological characteristics. Human Reproduction, 25(6), 1471-1480.

17. Ketabchi, A. A., and Ketabchi, M. (2011). Psychological effects of infertility in clinical varicocele patients. Health, 3(8), 504-506.

18. Omu, F. E., and Omu, A. E. (2010). Emotional reaction to diagnosis of infertility in Kuwait and successful clients' perception of nurses' role during treatment. BMC Nurs BMC Nursing, 9(1).
19. Ahmadi, H., Montaser-Kouhsari, L., Nowroozi, M. R., and Bazargan-Hejazi, S. (2011). Male infertility and depression: a neglected problem in the Middle East. J Sex Med, 8(3), 824-830.

20. Gao, J., Zhang, X., Su, P., Liu, J., Shi, K., Hao, Z., .. . Liang, C. (2013). Relationship between sexual dysfunction and psychological burden in men with infertility: a large observational study in China. J Sex Med, 10(8), 1935-1942.

21. Gadalla, A., Nasreldin, M., Mostafa, T., Ahmed, A., and Eid, A. (2011). Psychosexual satisfaction of infertile couples due to male factor infertility.Human Andrology, 1(2), 51-56.

22. Zorn, B., Auger, J., Velikonja, V., Kolbezen, M., and Meden-Vrtovec, H. (2008). Psychological factors in male partners of infertile couples: relationship with semen quality and early miscarriage. Int J Androl, 31(6), 557-564.

23. Sultan, S., and Tahir, A. (2011). Psychological consequences of infertility. Hellenic Journal of Psychology, 8(2), 229-247.

24. Keramat, A., Masoomi, S. Z., Mousavi, S. A., Poorolajal, J., Shobeiri, F., and Hazavhei, S. M. M. (2014). Quality of life and its related factors in infertile couples. Journal of research in health sciences, 14(1), 57-64.

25. Xing, X., Pan, B. C., Du, Q., Liang, X., Wang, X. M., and Wang, L. (2013). [Impact of male infertility on men's self-esteem and satisfaction with sexual relationship]. Zhonghua Nan Ke Xue, 19(3), 223-227. 